\title{
Uplift Behavior of Belled Short Piles in Weathered Sandstone
}

\author{
Bai Yang $\mathbb{D}$, Jianlin Ma $\mathbb{D}$, Wenlong Chen, and Yanxin Yang \\ School of Civil Engineering, Southwest Jiaotong University, Chengdu, Sichuan, 610031, China \\ Correspondence should be addressed to Jianlin Ma; majianlin01@126.com
}

Received 11 June 2018; Revised 22 August 2018; Accepted 30 August 2018; Published 16 September 2018

Academic Editor: Giovanni Minafò

Copyright (C) 2018 Bai Yang et al. This is an open access article distributed under the Creative Commons Attribution License, which permits unrestricted use, distribution, and reproduction in any medium, provided the original work is properly cited.

\begin{abstract}
Field pull out test results of $500 \mathrm{kV}$ double-circuit line of Luping-Fule are presented in this paper to investigate the uplift bearing behavior of rock-socketed belled short piles. A calculation model of rock-socketed belled short pile has been proposed. During the initial stage of loading test, uplift load is shared by even section and bell of the pile, and the bell continues to bear uplift load after the lateral resistance of even section pile reaches the limit. A different performance has been found on the case of long belled pile. At the ultimate state, the uplift resistance provided by bell accounts for about $54.9 \%$ and $34.7 \%$ of the total uplift capacity for the $6.0 \mathrm{~m}$ long and $7.0 \mathrm{~m}$ long piles, respectively. Increasing pile length has been found to noticeably increase the ultimate uplift bearing capacity, while it has less effect on the displacement of pile top. The uplift capacity of even section pile is associated with the shear strength of rock mass around the pile, and the test results demonstrate that the ultimate resistance can be equal to the shear strength. The calculation method proposed in this paper is proven to be able to accurately predict the ultimate uplift bearing capacity of the rock-socketed belled short piles.
\end{abstract}

\section{Introduction}

With the development of society and economy, uplift piles are widely used in high-rise buildings, underground space, transmission lines, offshore wind power, and other engineering practices. Compared with even section piles, belled piles can significantly increase the uplift bearing capacity with extra materials, which is favored in the project.

In the past decades, achievements have been made in the study of uplift piles with different methods. The study of uplift piles mainly focuses on the bearing behavior (influencing factors of bearing capacity) and the ultimate bearing capacity.

The key influence of pile length (Slenderness ratio, Embedment ratio) on ultimate bearing capacity has been verified in model tests and field tests [1-4]. The influence of rock or soil properties on the ultimate uplift capacity of piles is that the bearing capacity of piles in dense sand is much higher than in loose sand $[2,3,5-7]$. The uplift capacity of rocksocketed piles is controlled by the relative strength between piles and rocks when the material strength of piles is sufficient [8]; estimating the pulling capacity of piles in cohesive soils is based on an empirical relationship between soil adhesion and the undrained shear strength [1]. The effect of the loading method on the uplift capacity of piles is that the compressive loading can reduce the ultimate uplift capacity of piles $[9,10]$; the oblique loading can increase the ultimate uplift capacity of piles [11]; the combined loading can increase the uplift or lateral capacity of piles $[12,13]$. The increase of pile diameter can effectively increase the ultimate uplift capacity of piles (Lai Ying, 2010). Pile installation method is also affecting the uplift behavior. The bored piles yield higher shaft resistance than the driven piles [14], and the driven piles yield higher shaft resistance than the jacked piles [6]. The bearing capacity of rough piles is much higher than that of smooth piles $[6,15]$.

The failure mechanisms for piles subject to uplift loads mainly include vertical slip surface model, inverted truncated cone model, and curved slip surface model.

Several calculation models for ultimate bearing capacity have been proposed based on Figure 1 [15-20]. The abovementioned calculation models for the bearing capacity of uplift piles are mainly applied to the even section piles, while for the rock-socketed belled short piles, they are uncertain to apply. In this study, field tests were conducted to study the uplift behavior of rock-socketed belled short piles. According to the side resistance distribution of the piles, a method for calculating the ultimate bearing capacity of belled short piles was proposed. 
TABLE 1: Summary of properties of soil/sandstone and piles.

\begin{tabular}{lccccc}
\hline Names & $\gamma / \mathrm{kN} / \mathrm{m}^{3}$ & $c / \mathrm{kPa}$ & $\varphi /^{\circ}$ & $E / \mathrm{MPa}$ & \multicolumn{1}{c}{$f_{r} / \mathrm{MPa}$} \\
\hline Silty clay & 19.5 & 30 & 25 & - & 0.33 \\
Strong weathered sandstone & 24 & 400 & 32.8 & 80 & 0.25 \\
Medium Weathered sandstone & 25 & 1000 & 40.6 & 300 & 0.22 \\
Piles & 25 & - & - & 37000 & 0.2 \\
\hline
\end{tabular}

$\gamma$ is the unit weight, $c$ is the cohesion, $\varphi$ is the internal friction angle, $E$ is the elastic modulus, $\nu$ is the Poisson ratio, and $f_{r}$ is the uniaxial compressive strength.
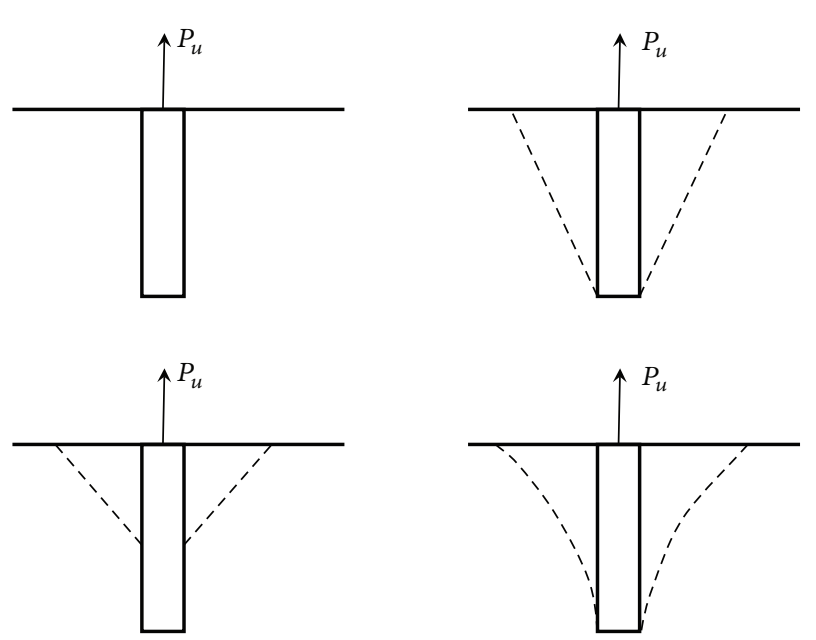

FIGURE 1: Assumed failure mechanisms for piles subject to uplift loads.

\section{Previous Studies on Belled Piles}

In recent years, achievements have been made in research of the belled pile. Dickin and Leung $[3,21]$ observed that the uplift capacity of belled piles is strongly dependent upon embedment ratio and sand density by centrifugal model tests. The influence of the shaft/bell diameter ratio and bell angle was suggested to be considered in the design of the uplift pile. Nazir [7] observed that the ultimate uplift capacity of belled piles was influenced by the embedment ratio, the shaft diameter, the base diameter, the base angle, and the soil density. According to the large-scale modelling experimental tests, Chae [22] conducted field tests and numerical analysis for belled piles in weathered sandstones and the geometric shape of the bell has more influence on the pile displacement than the bearing capacity. Niroumand [23] observed that the ultimate uplift capacity is dependent on the relative undrained or drained shear strength of cohesionless soil, the depth ratio of embedment, and soil thickness ratio. Moayedi [24] found that the bell can effectively reduce the ground surface deformation based on small scale tests and FEM studies.

The failure mechanisms for belled piles subject to uplift loads are great different from even section piles. Many scholars have proposed the idea that failure modes are shown in Figure 2 based on experimental results [25-27] and proposed the corresponding calculation method for the uplift capacity.
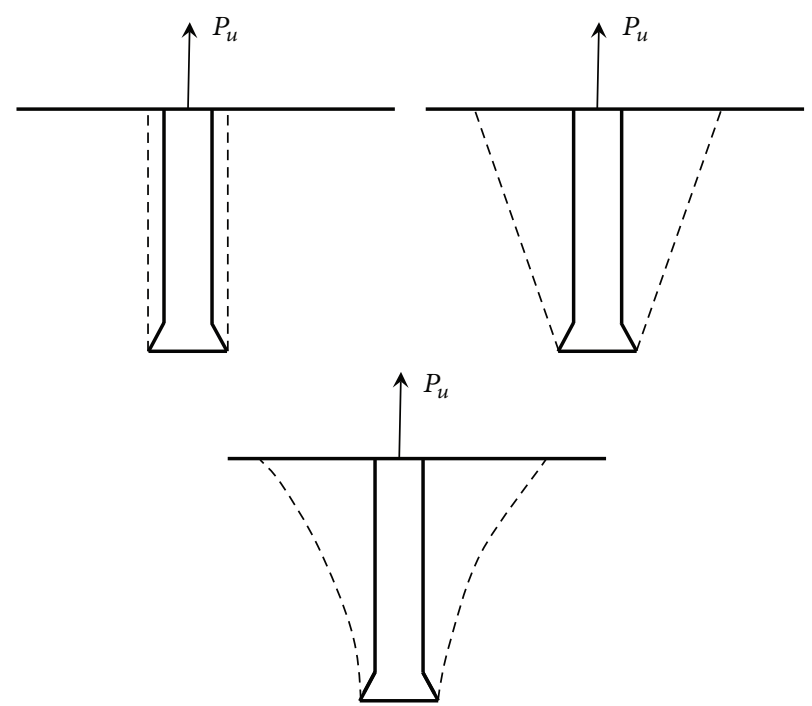

Figure 2: Assumed failure mechanisms for belled piles subject to uplift loads.

\section{Field Test}

3.1. Geological Conditions. The test site is located at the Hongxing Village, in Sichuan Province of China, and on the slope of the right bank of the Qingjiang River. The main strata are as follows: silty clay, about $0.3 \sim 3 \mathrm{~m}$ thick; strong weathered sandstone is about $0.5 \sim 3 \mathrm{~m}$ thick, a soft rock; medium weathered sandstone that is relatively complete. The joints and fractures are developed. The properties of soil, sandstone, and piles are summarized in Table 1.

3.2. Test Pile Design. The even section pile was mechanically drilled to form hole, and the bell was manually digged. The normalized height of the bell was one time pile diameter, bell diameter $D=d+2 \cdot 0.2 \mathrm{~m}$ ( $d$ is the shaft diameter). The overview of test piles is shown in Figure 3, and the dimensions of test piles are shown in Table 2. The concrete of test piles is C30, the longitudinal reinforcement of the steel cage is HRB500 grade rebar, the arrangement is $21 \Phi 36+4 \Phi 18$, the stirrups are HPB300, and the arrangement is 88@150. During the test, the displacement of the pile top was measured with displacement meters, and the axial force of the pile was measured with vibrating wire type steel bar gauges. A strain gauge is placed every $0.5 \mathrm{~m}$ down from the top of the pile up to the end of the pile. The elevation of each pile is set to $0.0 \mathrm{~m}$. 

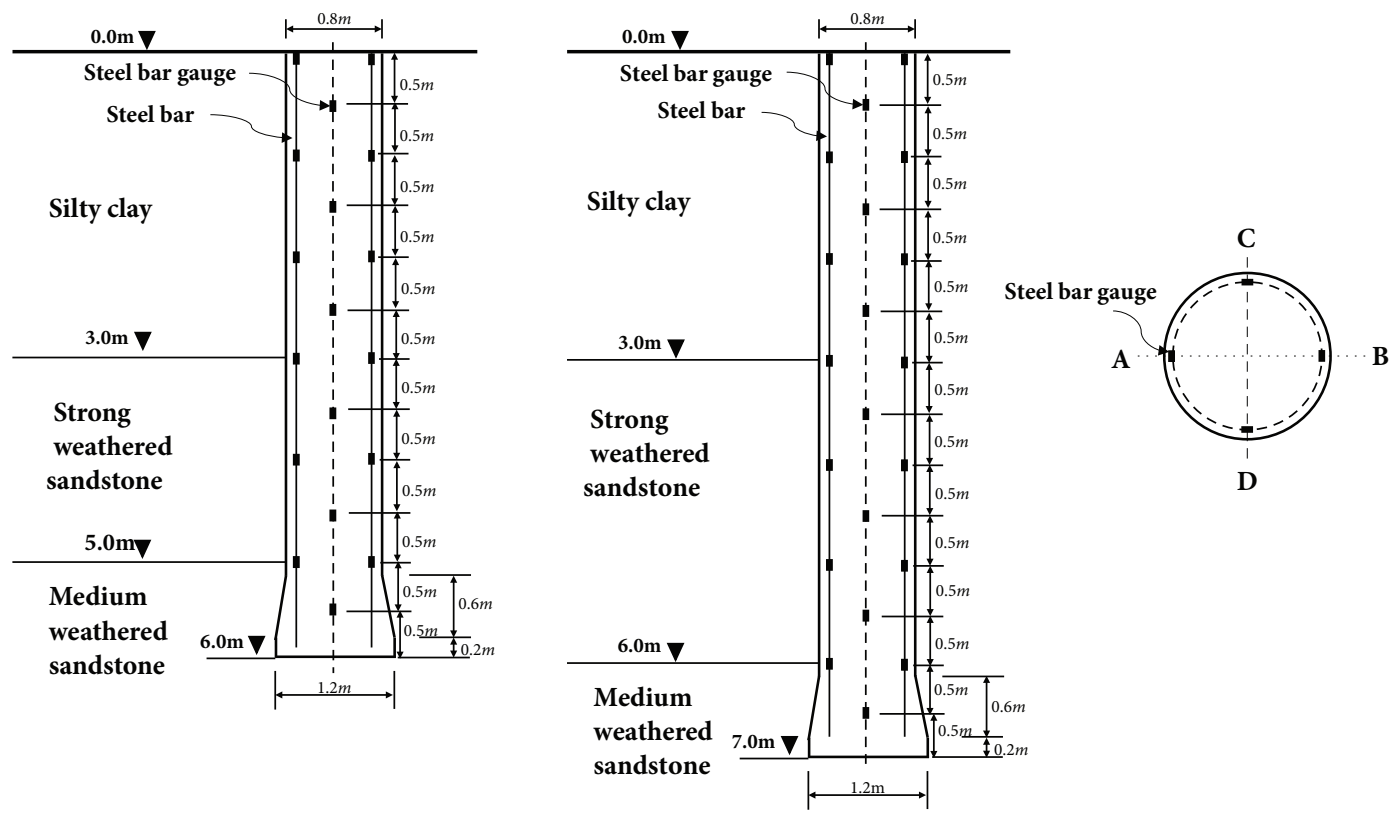

Figure 3: Profile of piles.

TABLE 2: Parameters of piles.

\begin{tabular}{lcccc}
\hline Pile No. & $d / \mathrm{m}$ & $D / \mathrm{m}$ & $L / \mathrm{m}$ & $H_{B} / \mathrm{m}$ \\
\hline TP1 & 0.8 & 1.2 & 6.0 & 0.8 \\
TP2 & 0.8 & 1.2 & 7.0 & 0.8 \\
\hline
\end{tabular}

$d$ is the shaft diameter, $D$ is the bell diameter, $L$ is the pile length, and $H_{B}$ is the bell height.

In order to reduce the influence of the eccentric load during loading, a $1.5 \times 1.5 \times 1.5 \mathrm{~m}$ pile cap is set on the pile top. The main tendons of the uplift pile extend into the reinforced concrete pile caps set on the top of the pile and are pulled up through the pile cap.

3.3. Test Programme. The test device consists of counterforce beams, hydraulic jacks, reaction piles (even section piles, the diameter is $0.8 \mathrm{~m}$, pile length is $6.6 \mathrm{~m}$ for TP1 and $7.6 \mathrm{~m}$ for TP2), and measuring devices. The maximum designed uplift ultimate load of the test pile is $12000 \mathrm{kN}$. Therefore, a $6000 \mathrm{kN}$ hydraulic jack is placed on each bearing and two hydraulic jacks are used in parallel to apply the vertical uplift force in parallel. The sum of the two loads is the uplift load of the test pile. The field test device is shown in Figure 4.

The test adopts the slow maintenance load method. During the test, when one of the following conditions is reached, the loading can be terminated.

(a) The top uplift load of the pile reaches 0.9 times of the total ultimate bearing capacity of the steel bar, or a certain steel bar is broken;

(b) Under a certain load, the pile top displacement is 5 times more than that under the previous stage of load;

(c) Cumulative displacement exceeds $100 \mathrm{~mm}$.

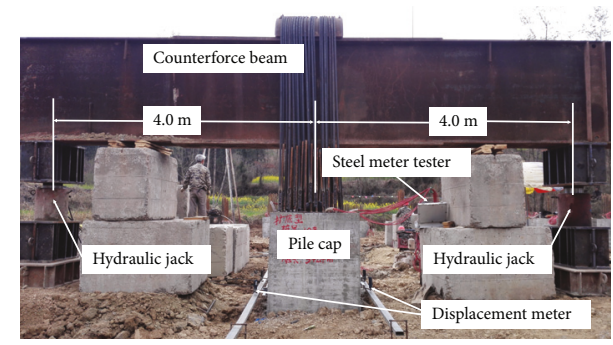

FIgURE 4: Site image of field test device.

TABLE 3: Results of pile tests.

\begin{tabular}{lcccc}
\hline Pile No & $P_{\max } / \mathrm{kN}$ & $S_{\max } / \mathrm{mm}$ & $P_{U} / \mathrm{kN}$ & $S_{U} / \mathrm{mm}$ \\
\hline TP1 & 6704 & $>38.3$ & 6328 & 20.6 \\
TP2 & 9626 & $>70.7$ & 8396 & 22.4 \\
\hline
\end{tabular}

$P_{\max }$ is the maximum uplift load, $S_{\max }$ is the maximum displacement of pile top, $P_{U}$ is the ultimate uplift load, and $S_{U}$ is the displacement of pile top under the ultimateuplift load.

\section{Test Results}

4.1. Load-Displacement Curve. The curve of the uplift load and pile top displacement of test piles are shown in Figure 5, and the test results are shown in Table 3.

Taking TP1 as an example, the test piles were lifted by $17.70 \mathrm{~mm}$ under the finial-stage load, which is 5 times more $(3.37 \times 5=16.85 \mathrm{~mm})$ than that under the load of the previous stage. The test piles reached the state of failure. Figure 6 shows that the top load-displacement curve at the top of two rock-socketed piles with deep-buried piles is steep, which is consistent with the pile top load in the soft soil area obtained by Wang [28]. 


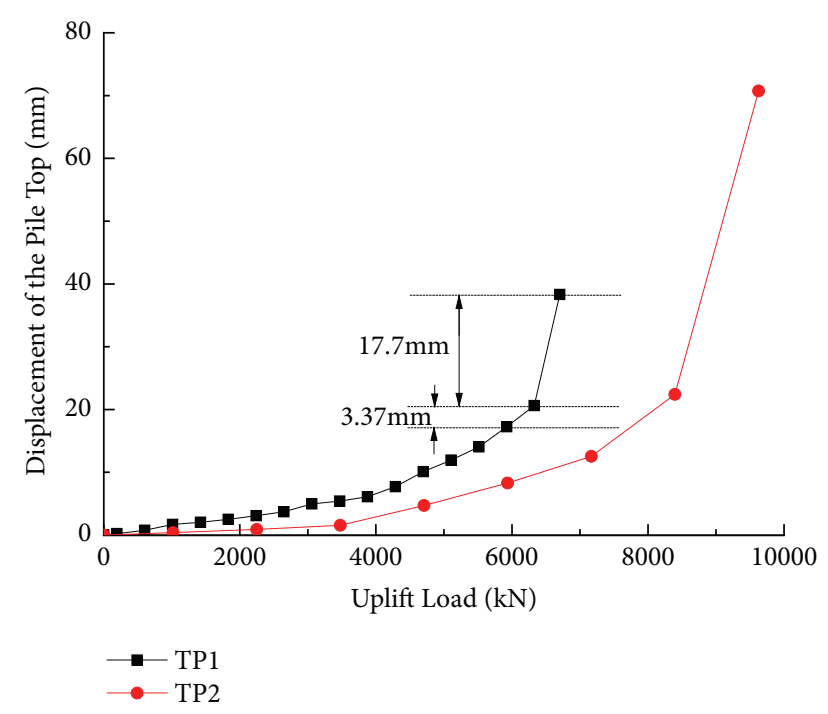

Figure 5: Load-displacement curve of pile top.

Uplift load of TP2 is $32.7 \%$ higher than TP1, indicating that increasing the pile length can increase the bearing capacity effectively, while the displacement of the pile top increases by $8.7 \%$, indicating that the effect of increasing pile length on the displacement of the pile top is limited.

\subsection{Axial Forces Distribution and Side Resistance Distribution} of Piles. The axial force of pile is obtained according to formula (1) by the reinforcing steel gauge stress at each section, and the side resistance of pile is obtained according to formula (2). The axial force distribution curve of 2 belled short piles under different loads is shown in Figure 6, and the side resistance distribution curve is shown in Figure 7.

$$
N_{i j}=\sigma_{i j} A_{s i}+\frac{\sigma_{i j} E_{s}}{E_{c}} A_{c i}
$$

where

$N_{i j}$ is the measured axial force of the pile under the stage load of the measured section,

$\sigma_{i j}$ is the measured stress of the steel bar stress meter under the stage load of the measured section,

$A_{s i}$ is the total area of the steel bar in the measured section,

$E_{c}$ is the elastic modulus of the concrete,

$E_{s}$ is the elastic modulus of the steel bar, and

$A_{c i}$ is the concrete area of the measured section.

$$
f_{i j}=\frac{N_{i j}-N_{(i-1) j}}{A_{i}}
$$

where

$f_{i j}$ is the side resistance of the $i \sim i+1$ section pile body under the stage load $j$,

$A_{i}$ is the pile side area within the $i \sim i+1$ measured sections, and
TABLE 4: Bearing capacities of the bell.

\begin{tabular}{lccc}
\hline Pile No & $P^{\prime} / \mathrm{kN}$ & $P_{U} / \mathrm{kN}$ & $P^{\prime} / P_{U}$ \\
\hline TP1 & 3472 & 6328 & $54.9 \%$ \\
TP2 & 2918 & 8396 & $34.7 \%$ \\
\hline
\end{tabular}

$P^{\prime}$ is the load provided by the bell and $P_{U}$ is the ultimate uplift load.

$N_{(i-1) j}$ is the axial force of the $i-1$ measured section under the stage load $j$.

Figure 6 shows that the axial force along the pile under the load at each stage gradually decreases along the depth, and the reduction rate varies among different rock and soil layers. As the load increases, the slope of the axial force curve in the overlying soil layer tends to be stable and the slope of the axial force curve in the rock layer continuously increases. The test pile shows different bearing behavior compared to the long belled pile (19m long pile, $30 \mathrm{~m}$ long pile) [28]. Figure 7 shows that, at the first stage of loading, side resistance of bell is ranging from 49.3 to $82.8 \mathrm{kPa}$ for TP1 and ranging from 148.6 to $274.5 \mathrm{kPa}$ for $\mathrm{TP} 2$, which is greater than the even section pile. It is observed that at, the initial stage of loading, the even section part of the pile and the bell part are bearing the uplift load at the same time. With the increase of the load, the lateral resistance of the even section pile continue to be mobilized until the limit is reached, and the bell continues to bear the uplift load.

According to the principle of force balance, the axial force curve of the pile provided by the rock and soil along the pile to a certain extent can respond to the pullout force. Taking the TP1 pile as an example, after the pile top acts more than $2239 \mathrm{kN}$, the rock resistance force provided by the rock exceeds $80 \%$ of the uplift force provided by the rock and soil layer and the ratio increases slightly with the increase of the pile top load. Under this effect, the ratio reached $85 \%$, indicating that the rock layer dominated the pullout resistance when the pile top load exceeds a certain value for overlying rock-socketed belled short uplift piles.

Because reinforcing bar gauges were not installed at the boundary between the bell and even sections, for the convenience of analysis, the slope of the axial force curve of the last measurement interval is extended to the interface between the even section and the bell section. The bell is obtained by measuring the axial force curve of the interval. Bearing capacities of the bell under ultimate uplift load of piles is shown in Table 4 .

Table 4 shows that, for rock-socketed belled short piles, with the increases of pile length, the proportion of the load provided by the bell will decreases. Therefore, for the longinlaid rock piles, the base-enlarging foundation should be used with caution.

\section{Calculation of Ultimate Uplift Capacity of Rock-Socketed Belled Short Piles}

The above analysis shows that the ultimate uplift bearing capacity of rock-socketed belled short piles consists of the side resistance and the pile weight. The side resistance 


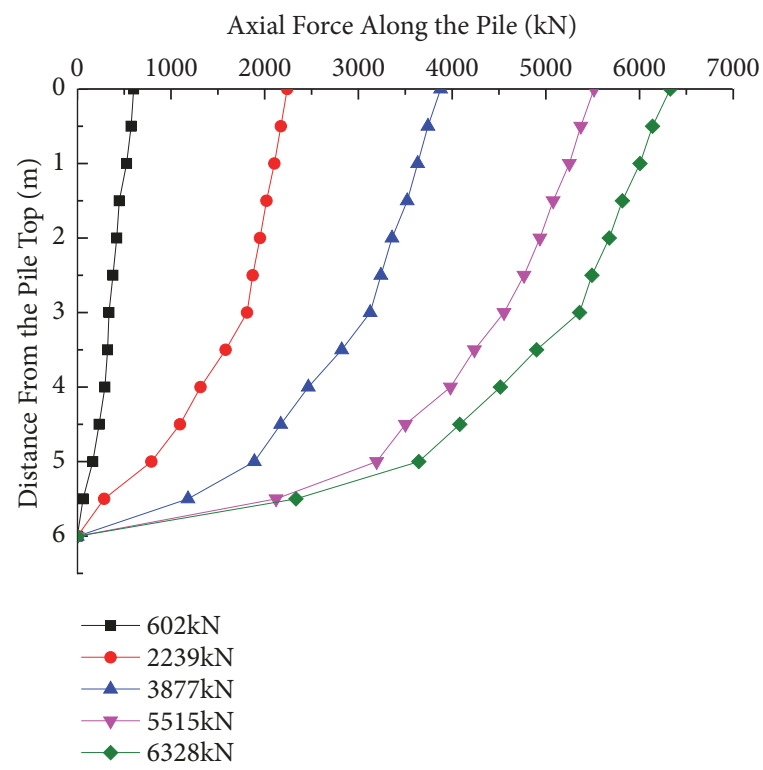

(a) TP1

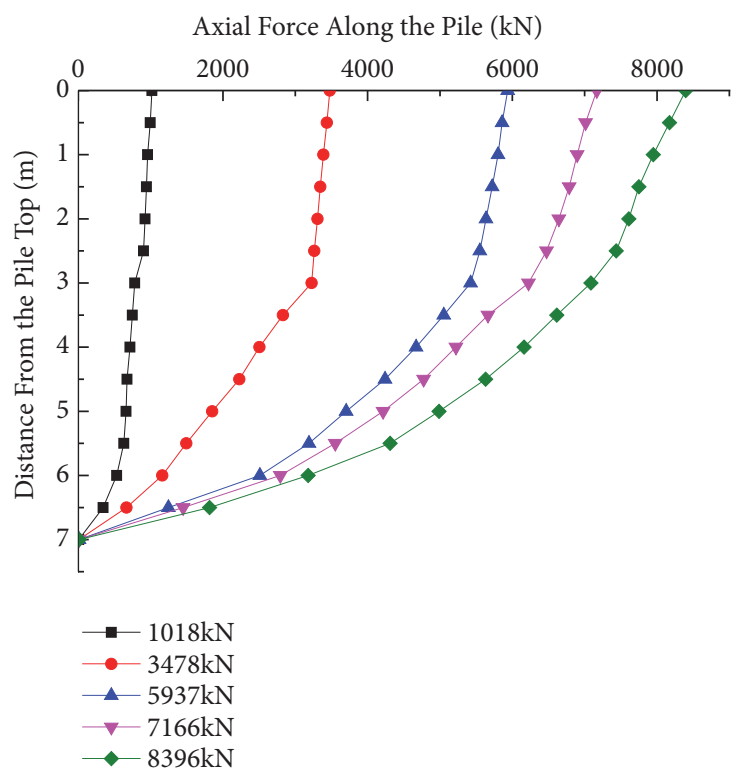

(b) TP2

Figure 6: Axial forces distribution along the pile.

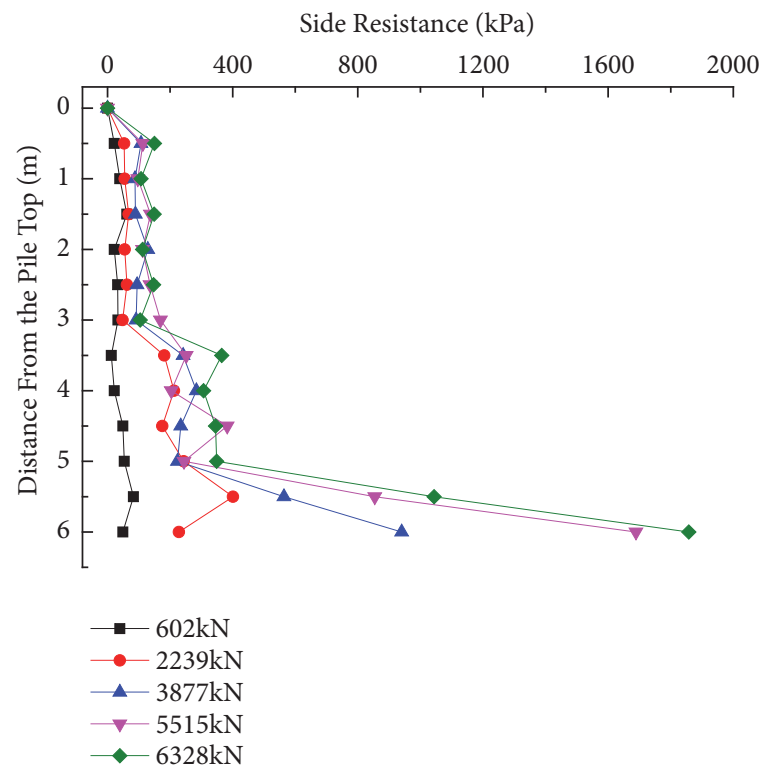

(a) TP1

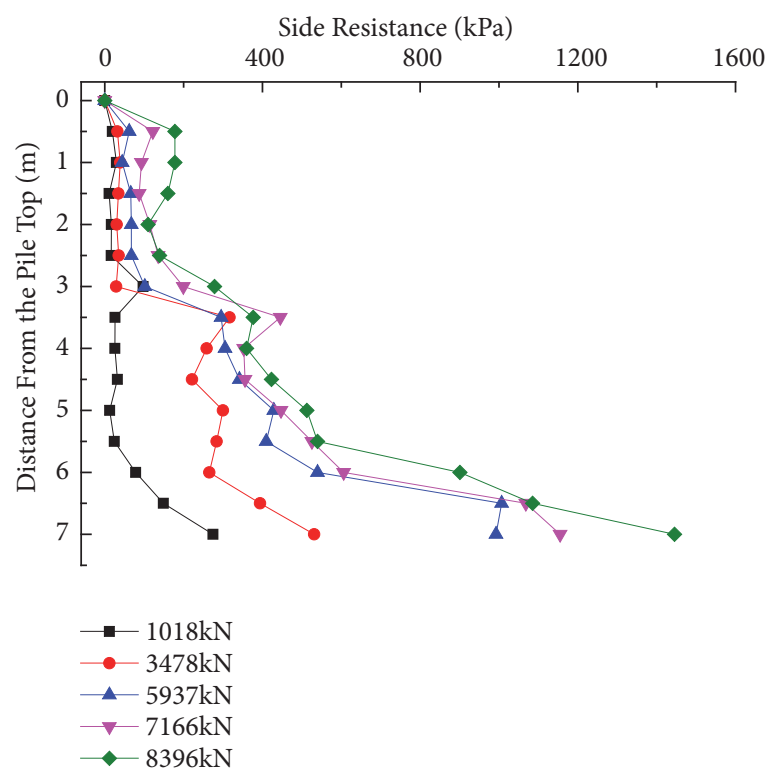

(b) TP2

FIGURE 7: Side resistance distribution of piles.

includes the side resistance provided by the even section pile and the expansion of the head-cone. Force diagram of the pile is shown in Figure 8.

Therefore, the formula for predicting ultimate uplift capacity of rock-socketed belled short piles can be expressed as follows:

$$
P_{U}=P_{S}+P_{B}+W_{C}=\sum \pi d_{i} L_{i} f_{s i}+S_{E} f_{B}+\gamma_{C} V
$$

where

$P_{S}$ is the uplift bearing capacity provided by the even section pile,
$P_{B}$ is the uplift bearing capacity by the expansion of the head-cone,

$W_{C}$ is the weight of the pile body,

$d_{i}$ is the pile diameter for the even section,

$L_{i}$ is the thickness of rock or soil layer,

$f_{s i}$ is the ultimate side resistance of the pile the rock and soil layer with even section,

$S_{E}$ is the area of the side of the cone-shaped conical table, 


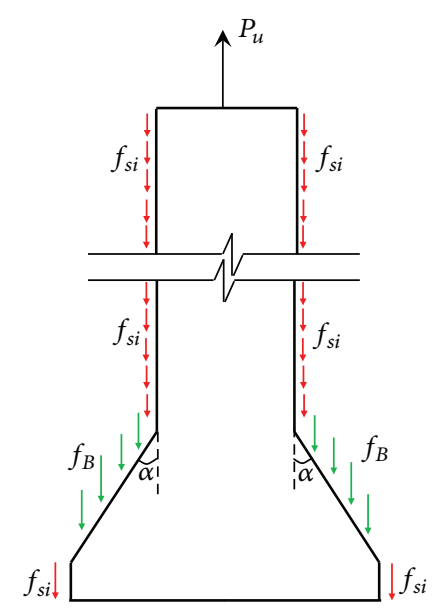

FIGURE 8: Force diagram of the pile.

$f_{B}$ is the ultimate side resistance value of the coneshaped conical table,

$\gamma_{C}$ is unit weight of pile, and

$V$ is the pile volume.

The geometric parameters in formula (3) can be calculated based on the test pile, but the values of $f_{s i}$ and $f_{B}$ need to be considered separately.

The value of the ultimate side resistance of the pile is mainly based on the code or the field test. The code values are generally conservative. Field test is high cost and takes a long time, which does not apply in small projects. Many scholars have concluded some relationships between the ultimate side resistance and the uniaxial compressive strength of rock. Exponential relationship [29-32] and linear relationship [33, $34]$ that facilitates the design work greatly.

5.1. Value of $f_{s i}$. During the loading test, pile and the surrounding rock mass generate slip surface that is governed by the strength of pile. If piles and rocks have the same strength, failure mode in such cases is expected to be the pull out of piles along with surrounding rocks attached. With the rock strength decreasing, the uplift bearing capacity of the pile gradually depends on rock strength. The pile and the surrounding rock mass are congealed. When the strength of the pile is higher, the slip surface is within the rock mass. The slip surface will be a cylindrical surface of which the diameter is similar to the pile diameter, and the surrounding rock mass is subjected only to the shear stress by the pile. During the early casting of rock-socketed piles, normal stress acts on the wall of the pile hole, while due to the structural planes in the rock mass, the normal stress gradually dissipates as the concrete solidifies. The pile body and the surrounding rock mass condensed. So the normal stress on the rock shear section was supposed to be nonexistent. The uplift bearing capacity of the pile is provided by the shear strength of the rock mass. The ultimate side resistance of the pile is equivalent to the shear strength of the rock mass. The soil has a continuous normal stress on the pile side. Within a certain depth range, with the increase of soil depth, the ultimate side

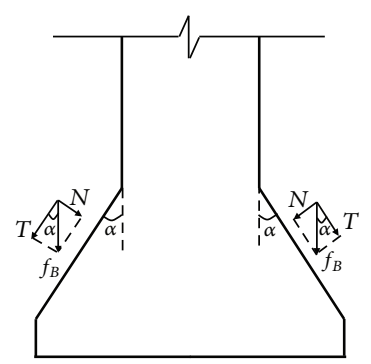

FIgURE 9: Force diagram of the conical side.

resistance of the pile also increases [14]. The ultimate side resistance of the clay layer can be based on the value of the clay undrained shear strength. The soil thickness of the test site in this paper is $3.0 \mathrm{~m}$, and the shear resistance of the soil at a depth of $1.5 \mathrm{~m}$ is selected.

By the Mohr-Coulomb strength criterion

$$
\begin{aligned}
& \tau=c+\sigma \tan \varphi . \\
& \sigma=\gamma \cdot \mathrm{z}
\end{aligned}
$$

where

$$
\begin{aligned}
& \tau \text { is the shear stress of silty clay, } \\
& \sigma \text { is the normal stress, and } \\
& \mathrm{z}=1.5 \mathrm{~m} .
\end{aligned}
$$

By formulas (4)-(5), the ultimate side resistance of the clay is obtained as $43.6 \mathrm{kPa}$.

For strong and medium weathered sandstone, where $\sigma=$ 0 , the shear strength of the strong and medium weathered sandstone is equal to the cohesion of the soil, which is $400 \mathrm{kPa}$ and $1000 \mathrm{kPa}$, respectively, and it is equal to the ultimate side resistance of the rock mass surrounding the pile.

5.2. Value of $f_{B}$. When the uplift load is applied, the external force on the conical side is shown in Figure 9.

By the Mohr-Coulomb strength criterion

$$
T=c+N \tan \varphi
$$

where

$N$ is the normal stress provided by the rock mass and

$T$ is the side resistance along the bell.

By the balance condition of force

$$
N \cos \alpha=T \sin \alpha
$$

where

$\alpha$ is the inclination angle of bell.

$$
f_{B}=\sqrt{N^{2}+T^{2}}
$$

by formulas (6)-(8), $f_{B}=1476 \mathrm{kPa}$.

The value of each parameter is brought into formula (3) to determine the ultimate bearing capacity of the uplift piles. 
TABLE 5: Comparison of results.

\begin{tabular}{lllr}
\hline Pile No. & Field test & This approach & Method of friction cylinder \\
\hline TP1 & $6328(100 \%)$ & $6968(110.1 \%)$ & $7981(126.1 \%)$ \\
TP2 & $8396(100 \%)$ & $7985(95.1 \%)$ & $9516(113.3 \%)$ \\
\hline
\end{tabular}

The friction cylinder method [35] is used to apply in calculating the uplift capacity of rock-socketed belled piles and the formula is as follows:

$$
P_{U}=\left(\pi D \sum \lambda_{i} q_{s i k} l_{i}+\pi D \sum h_{j} f_{r s i}\right)+W_{C}+W_{r}
$$

where

$\lambda_{i}$ is the uplift coefficient,

$q_{s i k}$ is ultimate compressive side friction value for soil of $i$ layer of pile's surface,

$l_{i}$ is the thickness of soil of $i$ layer,

$h_{j}$ is the thickness of rock of $j$ layer,

$f_{r s i}$ is the rock shear strength of each layer,

$W_{C}$ is the weight of the pile body, and

$W_{r}$ is the weight of rock and soil above pile's bottom.

The field test results, calculation results of this paper, and method of friction cylinder are compared, as shown in Table 5.

As it can be seen from Table 5 that the calculation model proposed in this study can accurately calculate the ultimate uplift bearing capacity of the rock-socketed belled short pile and can be applied to similar projects.

\section{Conclusions}

In this paper, the uplift behavior of rock-socketed belled short piles is studied based on field test results. A semiempirical method for calculating the ultimate uplift capacity of rocksocketed belled short piles has been proposed. The following main conclusions are drawn.

The rock-socketed belled short pile showed different bearing behavior compared to the long belled pile during the field tests. At the initial stage of loading, the even section pile and the bell take up the uplift load synchronously. With the increase of the load, the lateral resistance of the even section pile continue worked until the limit is reached and the bell continues to bear the uplift load. At the ultimate state, the uplift resistance provided by the bell accounts for about $54.9 \%$ and $34.7 \%$ of the total uplift capacity for the $6.0 \mathrm{~m}$ long and $7.0 \mathrm{~m}$ long piles, respectively. The increase of the pile length can effectively increase the ultimate uplift bearing capacity, while it has less effect on the displacement of the pile top. The influence of the bell has weakened with the increase of the pile length. When the strength of the pile exceeds that of the rock mass around pile, the uplift capacity of the even sections is provided by the shear strength of the rock mass and the ultimate side resistance becomes equal to the shear strength of the rock mass around the pile. The calculation method proposed in this paper can accurately calculate the ultimate uplift bearing capacity of the rock-socketed belled short piles.

\section{Data Availability}

The data used to support the findings of this study are available from the corresponding author upon request.

\section{Conflicts of Interest}

The authors declare that they have no conflicts of interest.

\section{Acknowledgments}

This research was supported by the National Key Project of Research \& Development Plan (2016YFC0802203). In addition, Bai Yang wants to thank his wife Baokui Huang for her support and encouragement over the years and welcomes their first child to this wonderful world.

\section{References}

[1] V. A. Sowa, "Pulling capacity of concrete cast in situ bored piles," Canadian Geotechnical Journal, vol. 7, no. 4, pp. 482-493, 1970.

[2] B. M. Das, G. R. Seeley, and T. W. Pfeifle, "Pullout resistance of rough rigid piles in granular soil," Soils and Foundations, vol. 17, no. 3, pp. 72-77, 1977.

[3] E. A. Dickin and C. F. Leung, "Performance of piles with enlarged bases subject to uplift forces," Canadian Geotechnical Journal, vol. 27, no. 5, pp. 546-556, 1990.

[4] K. Faizi, R. Kalatehjari, R. Nazir, and A. S. A. Rashid, "Determination of pile failure mechanism under pullout test in loose sand," Journal of Central South University, vol. 22, no. 4, pp. 1490-1501, 2015.

[5] K. S. Rao and K. H. Venkatesh, "Uplift behaviour of short piles in uniform sand," Soils and Foundations, vol. 25, no. 4, pp. 1-7, 1985.

[6] A. S. Alawneh, A. I. Husein Malkawi, and H. Al-Deeky, "Tension tests on smooth and rough model piles in dry sand," Canadian Geotechnical Journal, vol. 36, no. 4, pp. 746-753, 1999.

[7] R. Nazir, H. Moayedi, A. Pratikso, and M. Mosallanezhad, "The uplift load capacity of an enlarged base pier embedded in dry sand," Arabian Journal of Geosciences, vol. 8, no. 9, pp. 72857296, 2015.

[8] X. Wu, Z. Yu Q, and Z. Yuan W, "Uplift pile test in rocks and its bearing capacity," Journal of Southwest Jiaotong University, vol. 10, no. 01, pp. 84-89, 2002 (Chinese).

[9] B. K. Dash and P. J. Pise, "Effect of compressive load on uplift capacity of model piles," Journal of Geotechnical and Geoenvironmental Engineering, vol. 129, no. 11, pp. 987-992, 2003. 
[10] A. Shelke and N. R. Patra, "Effect of Compressive Load on Uplift Capacity of Cast-Insitu Bored Piles," Geotechnical and Geological Engineering, vol. 29, no. 5, pp. 927-934, 2011.

[11] E. C. Shin, B. M. Das, V. K. Puri, S. C. Yen, and E. E. Cook, "Ultimate uplift capacity of model rigid metal piles in clay," Geotechnical and Geological Engineering, vol. 11, no. 3, pp. 203215, 1993.

[12] R. Ayothiraman and K. M. Reddy, "Model experiments on pile behaviour in loose-medium dense sand under combined uplift and lateral loads," in Proceedings of the 2014 GeoShanghai International Congress: Tunneling and Underground Construction, pp. 633-643, China, May 2014.

[13] K. M. Reddy and R. Ayothiraman, "Experimental studies on behavior of single pile under combined uplift and lateral loading," Journal of Geotechnical and Geoenvironmental Engineering, vol. 141, no. 7, Article ID 04015030, 2015.

[14] N. F. Ismael and H. A. Al-Sanad, "Uplift Capacity of Bored Piles in Calcareous Soils," Journal of Geotechnical Engineering, vol. 112, no. 10, pp. 928-940, 1986.

[15] B. C. Chattopadhyay and P. J. Pise, "Uplift capacity of piles in sand," Journal of Geotechnical Engineering, vol. 112, no. 9, pp. 888-904, 1986.

[16] G. Meyerhof, "Uplift resistance of inclined anchors and piles," in Proceedings of the 8th International Conference on Soil Mechanics and Foundation Engineering, vol. 12, pp. 167-172, Kluwer Academic Publishers-Plenum Publishers, Moscow, Russia, 1973.

[17] B. M. Das, "Procedure for estimation of uplift capacity of rough piles," Soils and Foundations, vol. 23, no. 3, pp. 122-126, 1983.

[18] K. Shanker, P. K. Basudhar, and N. R. Patra, "Uplift capacity of single piles: Predictions and performance," Geotechnical and Geological Engineering, vol. 25, no. 2, pp. 151-161, 2007.

[19] G. Q. Kong, Q. Yang, M. Wang, and M. T. Luan, "Uplift capacity of single piles embedded in clay: Prediction and application," in Proceedings of the International Young Scholars' Symposium on Rock Mechanics - Boundaries of Rock Mechanics Recent Advances and Challenges for the 21st Century, pp. 625-629, China, May 2008.

[20] W.-P. Hong and N. Chim, "Prediction of uplift capacity of a micropile embedded in soil," KSCE Journal of Civil Engineering, vol. 19, no. 1, pp. 116-126, 2014.

[21] E. A. Dickin and C. F. Leung, "The influence of foundation geometry on the uplift behaviour of piles with enlarged bases," Canadian Geotechnical Journal, vol. 29, no. 3, pp. 498-505, 1992.

[22] D. Chae, W. Cho, and H.-Y. Na, "Uplift capacity of belled pile in weathered sandstones," International Journal of Offshore and Polar Engineering, vol. 22, no. 4, pp. 297-305, 2012.

[23] H. Niroumand, K. A. Kassim, A. Ghafooripour, and R. Nazir, "Uplift capacity of enlarged base piles in sand," Electronic Journal of Geotechnical Engineering, vol. 17, pp. 2721-2737, 2012.

[24] H. Moayedi and M. Mosallanezhad, "Uplift resistance of belled and multi-belled piles in loose sand," Measurement, vol. 109, pp. 346-353, 2017.

[25] J. Majer, "Zur Berechnung von Zugfundamenten," Osterreichische Bauzeitschrift, vol. 10, no. 5, pp. 85-90, 1955.

[26] G. G. Meyerhof and J. I. Adams, "Ultimate uplift capacity of foundations," Canadian Geotechnical Journal, vol. 5, no. 4, pp. 225-244, 1968.

[27] E. J. Murray and J. D. Geddes, "Uplift of anchor plates in sand," Journal of Geotechnical Engineering, vol. 113, no. 3, pp. 202-215, 1987.
[28] W. Wang D, J. Wu B, and J. Wang X, "Ultimate load tests on bearing and deformation behavior of uplift piles with enlarged base," Chinese Journal of Geotechnical Engineering, vol. 38, no. 7, pp. 1330-1337, 2016.

[29] P. Rosenberg and N. L. Journeaux, "Friction and end bearing tests on bedrock for high capacity socket design," Canadian Geotechnical Journal, vol. 13, no. 3, pp. 324-333, 1976.

[30] R. K. Rowe and H. H. Armitage, "Theoretical solutions for axial deformation of drilled shafts in rock," Canadian Geotechnical Journal, vol. 24, no. 1, pp. 114-125, 1987.

[31] Z. Lianyang and H. H. Einstein, "End bearing capacity of drilled shafts in rock," Journal of Geotechnical and Geoenvironmental Engineering, vol. 124, no. 7, pp. 574-584, 1998.

[32] C. W. W. Ng, T. L. Y. Yau, J. H. M. Li, and W. H. Tang, "Side resistance of large diameter bored piles socketed into decomposed rocks," Journal of Geotechnical and Geoenvironmental Engineering, vol. 127, no. 8, pp. 642-657, 2001.

[33] T. J. Kaderabek and R. T. Reynolds, "Miami limestone foundation design and construction," Journal of the Geotechnical Engineering Division, vol. 107, no. 7, pp. 859-872, 1981.

[34] C. Toh T, T. Ooi A, and H. Chiu K, "Design parameters for bored piles in a weathered sedimentary Formation," in Proceedings of the 12th International Conference on Soil Mechanics and Foundation Engineering, pp. 1073-1078, Rio de Janerio, Brazil, 1989.

[35] H. He, G. L. Dai, and W. Gong, "Prediction of bearing capacity for rock-socketed under-reamed uplift piles based on HoekBrown failure criterion," in Proceedings of the Geo-Hubei 2014 International Conference on Sustainable Infrastructure: Recent Advances in Material, Analysis, Monitoring, and Evaluation in Foundation and Bridge Engineering, pp. 54-61, China, July 2014. 


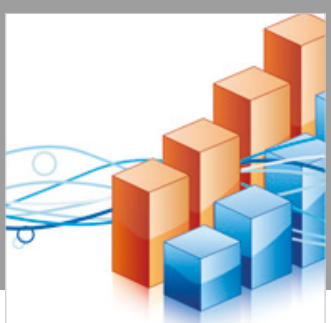

Advances in

Operations Research

\section{-n-m}
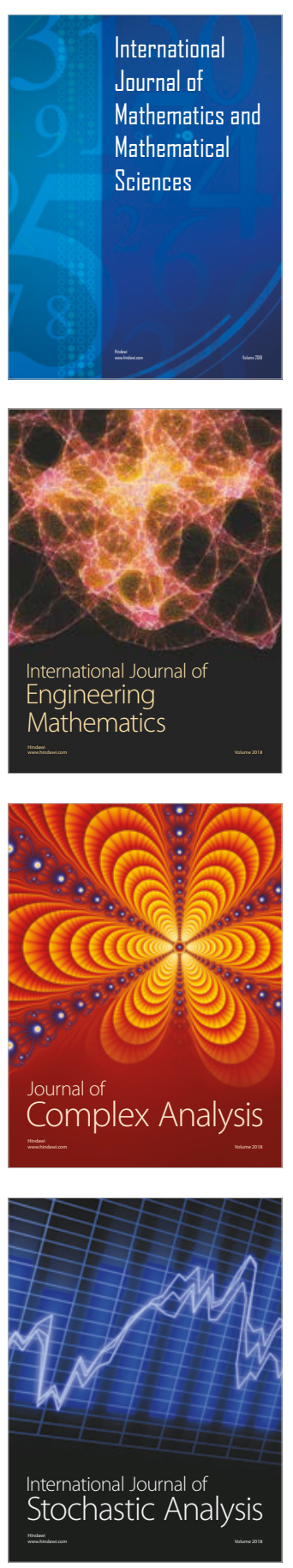
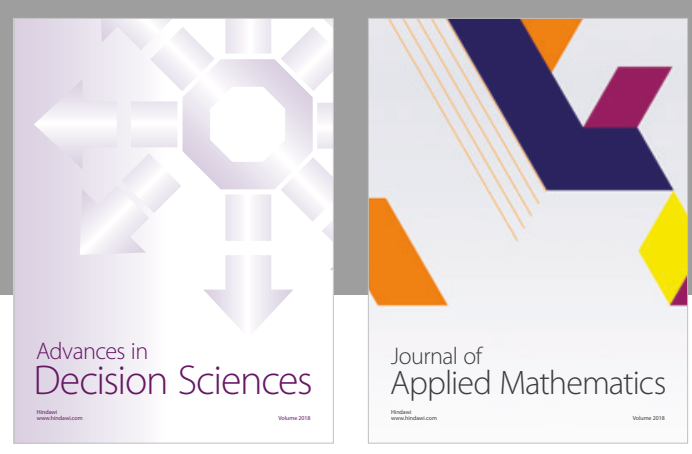

Journal of

Applied Mathematics
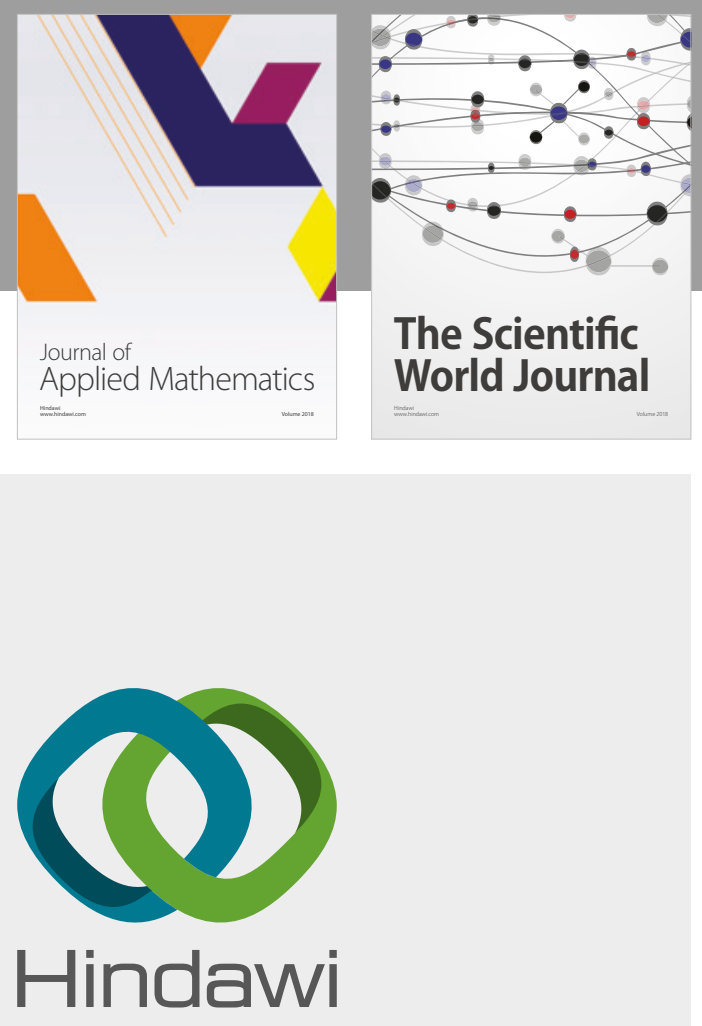

Submit your manuscripts at

www.hindawi.com

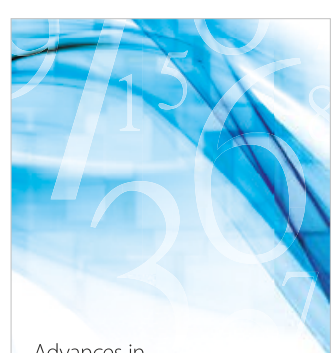

Advances in
Numerical Analysis
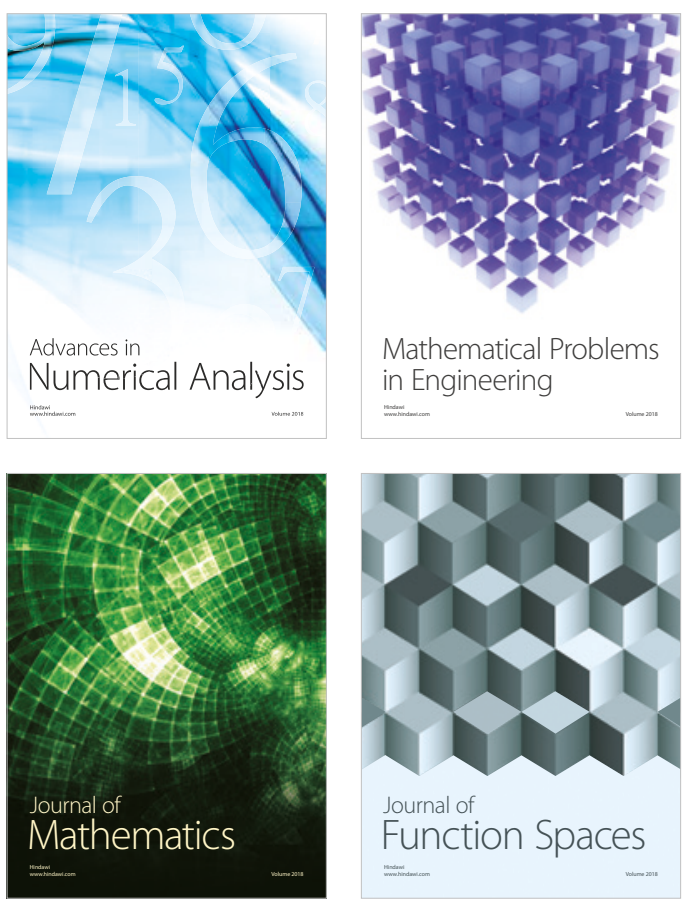

Mathematical Problems in Engineering

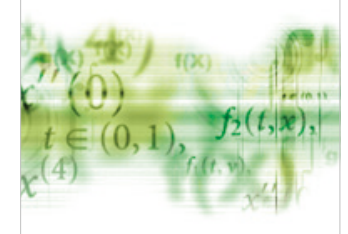

International Journal of

Differential Equations

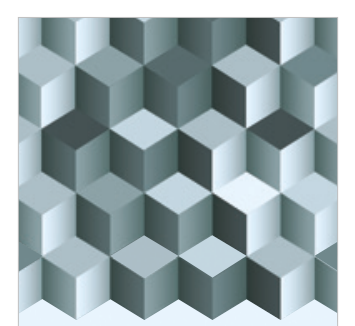

Journal of

Function Spaces

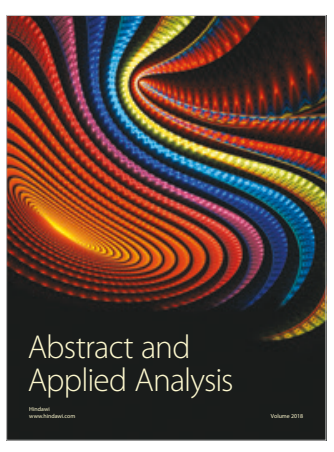

The Scientific

World Journal

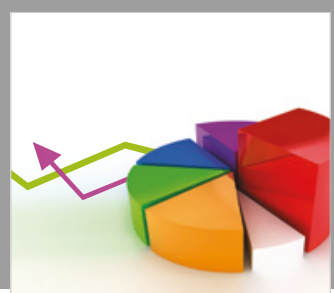

Journal of

Probability and Statistics
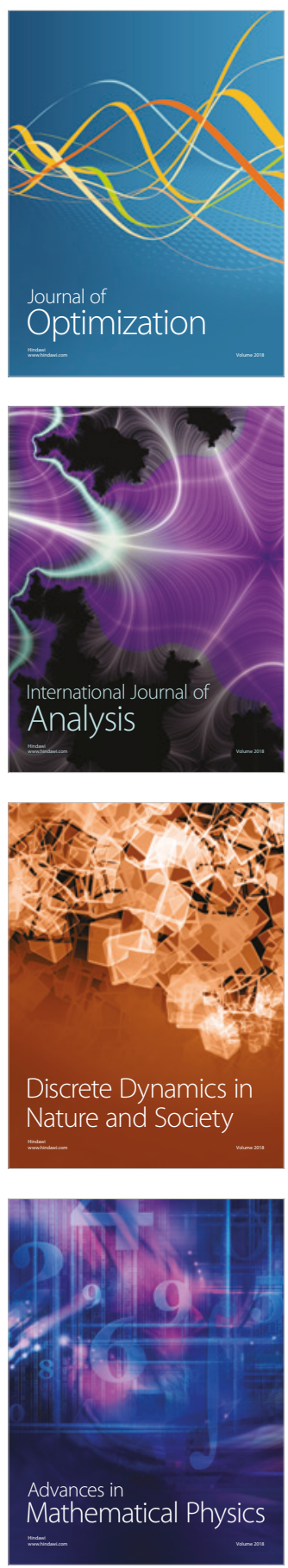